\title{
La industria colombiana 1975-2014: inequidad entre trabajo y capital
}

\section{Colombian Industry 1975-2014: Inequity between Labor and Capital}

\section{A Indústria Colombiana 1975-2014: desigualdade entre trabalho e capital}

\author{
Julio Silva-Colmenares*
}

Carolina Padilla Pardo**

* PhD en economía (summa cum laude) de la Escuela Superior de Economía de Berlín y doctor en Ciencias Económicas de la Universidad de Rostock (Alemania); profesor-investigador y director del Observatorio sobre Desarrollo Humano de la Universidad Autónoma de Colombia, Bogotá-Colombia; profesor visitante de postgrado en varias universidades; obdehumano@fuac.edu.co (iD http://orcid.org/0000-0003-4562-7328

** Profesional en Relaciones Económicas Internacionales; economista y especialista en Gerencia Financiera; cursante de la Maestría (a distancia) en Desarrollo Humano de FLACSO, Argentina; profesional adscrita al Observatorio sobre Desarrollo Humano de la Universidad Autónoma de Colombia, Bogotá-Colombia; rei.carolina.pp@gmail.com auxobdehum@fuac.edu.co (iD http://orcid.org/0000-0001-8624-1582 


\title{
Resumen
}

Como parte de una investigación sobre transnacionalización del gran capital colombiano, se analiza la distribución funcional de la riqueza creada en la industria durante casi 40 años. Se destacan los cambios en la composición de su producción bruta, así como la concentración de la producción y la centralización del capital, fenómenos liderados por grupos financieros que datan del siglo pasado. También se indaga sobre la evolución de la productividad laboral y del empleo, y los eventuales efectos de los cambios tecnológicos en este sector. Se concluye que en la distribución del valor agregado industrial gana peso relativo el capital, con detrimento de la parte que corresponde al trabajo.

Palabras clave: industria, distribución funcional del ingreso, empresas transnacionales, grupos financieros, productividad laboral, riqueza.

Clasificación JEL: L60, L16, D33, F23, J24, D31

\begin{abstract}
As part of a research about transnationalization of the large Colombian capital, functional distribution of the wealth created in the industry for nearly 40 years is analyzed. The changes in the composition of its gross output and the concentration of production and centralization of capital, phenomena led by financial groups dating from the last century, are stand out. It also explores the evolution of labor productivity and employment, and the possible effects of technological change in this sector. It is concluded that in the industrial value added distribution, capital gains weight relative to the detriment of the share of the work.
\end{abstract}

Keywords: industry, functional income distribution, transnational corporations, financial groups, labor productivity, wealth. 


\section{Resumo}

Como parte de uma pesquisa sobre transnacionalização da grande capital colombiana, é analisada a distribuição funcional da riqueza criada na indústria por quase 40 anos. Destacam-se as mudanças na composição de sua produção bruta e a concentração da produção e centralização do capital, fenômenos liderados por grupos financeiros do século passado. Ele também explora a evolução da produtividade do trabalho e do emprego e os possíveis efeitos da mudança tecnológica neste setor. Conclui-se que na distribuição de valor agregado industrial, os ganhos de capital ganham peso em detrimento da parcela do trabalho.

Palavras-chave: indústria, distribuição funcional de renda, empresas transnacionais, Grupos financeiros, produtividade do trabalho, riqueza. 


\section{CAMBIOS EN LA COMPOSICIÓN DE LA PRODUCCIÓN BRUTA INDUSTRIAL}

En una investigación que adelantan lo autores de este artículo sobre los eventuales efectos internos de la transnacionalización de grandes empresas y conglomerados colombianos -efectos que deben existir, aunque no es fácil detectarlos-, muchos pertenecientes a los principales grupos financieros del país, uno de los objetivos es analizar la evolución de la industria manufacturera ${ }^{1}$ durante el lapso 1975-2014, con base en la nueva serie del Sistema de Cuentas Nacionales que publica el Departamento Administrativo Nacional de Estadística (DANE) con base 2005, en donde al mismo tiempo se ha ampliado la "canasta" de bienes y servicios que comprenden el PIB, pues de este sector proviene la mayoría de los conglomerados que se han proyectado hacia el exterior ${ }^{2}$, teniendo presencia directa en dos o más países diferentes a Colombia (SilvaColmenares \& Padilla-Pardo, 2015). Como lo han comprobado distintas investigaciones, en muchos países el peso relativo del consumo intermedio en la composición básica de la producción industrial ha aumentado, con disminución del otro componente, el valor agregado, al tiempo que también se ha modificado la composición del valor agregado con detrimento de la parte porcentual que corresponde a la remuneración al trabajo humano e incremento de la parte

$1 \quad$ Según el DANE, la industria manufacturera "se define como la transformación mecánica o química de sustancias orgánicas e inorgánicas en productos nuevos, ya sea que el trabajo se efectúe con máquinas o a mano, en fábrica o a domicilio, o que los productos se vendan al por mayor o al por menor. Incluye el montaje de las partes que componen los productos manufacturados, excepto en los casos en que tal actividad sea propia del sector de la construcción".

2 De los 42 conglomerados analizados en este libro, la mayor parte, 18, provienen de la industria manufacturera. 
que va para el capital y otros factores no salariales. Pero esto último no solo ocurrió en la industria, sino para todo el conjunto de la economía.

En la conocida investigación de Thomas Piketty (1971) sobre la distribución funcional del ingreso nacional en algunos países ricos, la situación descrita fue la encontrada. Para el caso de su país, Francia, observa que "el reparto beneficios-sueldos conoció tres fases muy distintas desde la Segunda Guerra Mundial, con una fuerte alza de la participación de los beneficios de 1945 a 1968, luego una baja sumamente pronunciada de 1968 a 1983 y, por último, una subida muy rápida a partir de 1983 y una estabilización a partir de principios de los años noventa. [...]". En nota al pie de la gráfica VI.6 de su libro El capital en el siglo $X X I$ recalca que: "La participación de los beneficios brutos en el valor agregado bruto de las empresas pasó de 25\% en 1982 a 33\% en 2010”, al tiempo que explica, en nota al pie de página y en coincidencia con el concepto utilizado en el párrafo anterior, que:

El ‘valor agregado’ de una empresa se define como la diferencia entre el valor de las ventas de bienes y servicios (monto llamado chiffre d'affaires en la contabilidad francesa y sales revenue en inglés) y lo que le cuestan sus compras a otras empresas (monto llamado 'consumo intermedio'). Como su nombre lo indica, esta suma calcula el valor que la empresa añadió al proceso de producción. El valor agregado permite pagar la masa salarial y el resto constituye, por definición, los beneficios de la empresa. [...]. (Piketty, 2014, p. 249)

Esto significa que la masa salarial pasó del 75 \% en 1982 al 67 \% en 2010.

En la Tabla 1 se muestran los valores absolutos y relativos encontrados para esos conceptos durante los últimos diez gobiernos nacionales en la industria colombiana, en donde cada gobierno se toma como un momento histórico para facilitar la comparación, esto es, los valores absolutos para cada concepto o variable corresponden a la suma del respectivo cuatrienio, convertidos los valores corrientes a pesos del año 2005 , utilizando los resultados del Sistema de Cuentas Nacionales base 2005 para la deflactación. Los valores relativos corresponden al cálculo sobre esos valores acumulados. 
La industria colombiana 1975-2014: inequidad entre trabajo y capital Julio Silva-Colmenares - Carolina Padilla Pardo

Tabla 1. Industria 1975-2014: participación del valor agregado en la producción bruta y composición del valor agregado

\begin{tabular}{|l|l|l|l|l|l|l|l|}
\hline \multicolumn{1}{|c|}{ GOBIERNOS } & PB bn\$ & VA bn\$ & RT bn\$ & EB bn\$ & \% VA/PB & \%RT/VA & \% E B/VA \\
\hline Alfonso López Michelsen (1975-1978) & 252,0 & 104,1 & 32,5 & 71,6 & $41,3 \%$ & $31,2 \%$ & $68,8 \%$ \\
\hline Julio César Turbay Ayala (1979-1982) & 286,9 & 122,4 & 39,8 & 82,6 & $42,7 \%$ & $32,5 \%$ & $67,5 \%$ \\
\hline Belisario Betancur C. (1983-1986) & 300,4 & 120,6 & 40,5 & 80,0 & $40,1 \%$ & $33,6 \%$ & $66,4 \%$ \\
\hline Virgilio Barco Vargas (1987-1990) & 376,9 & 145,2 & 40,4 & 104,8 & $38,5 \%$ & $27,8 \%$ & $72,2 \%$ \\
\hline César Gaviria Trujillo (1991-1994) & 384,0 & 157,0 & 47,6 & 109,4 & $40,9 \%$ & $30,3 \%$ & $69,7 \%$ \\
\hline Ernesto Samper Pisano (1995-1998) & 374,3 & 168,7 & 49,4 & 119,3 & $45,1 \%$ & $29,3 \%$ & $70,7 \%$ \\
\hline Andrés Pastrana Arango (1999-2002) & 355,8 & 157,1 & 39,9 & 117,1 & $44,1 \%$ & $25,4 \%$ & $74,6 \%$ \\
\hline Álvaro Uribe Vélez (2003-2006) & 436,8 & 187,7 & 36,6 & 151,1 & $43,0 \%$ & $19,5 \%$ & $80,5 \%$ \\
\hline Álvaro Uribe Vélez (2007-2010) & 489,4 & 214,9 & 41,0 & 173,9 & $43,9 \%$ & $19,1 \%$ & $80,9 \%$ \\
\hline Juan Manuel Santos (2011-2014) & 569,5 & 219,6 & 43,5 & 176,1 & $38,6 \%$ & $19,8 \%$ & $80,2 \%$ \\
\hline$\%$ de variación 2011-14/1975-78 & $125,9 \%$ & $110,9 \%$ & $33,9 \%$ & $145,8 \%$ & & \multicolumn{5}{c}{} \\
\hline
\end{tabular}

Fuente: DANE, Encuestas anuales manufactureras - EAM- Cálculos de los autores.

$\mathrm{PB}=$ Pruducción Bruta

$\mathrm{VA}=$ Valor Agregado

RT = Remuneración total a Trabajadores

$\mathrm{EB}=$ Excedente Bruto (VA-RT)

bn $\$=$ Billones de pesos de 2005 (Acumulado del cuatrienio)

Como se observa en la Tabla 1, en el curso de los 40 años la producción bruta industrial ${ }^{3}$ aumentó en 2,3 veces, mientras que el valor agregado aumentó en 2,1 veces, lo que implica que el valor agregado como proporción de la producción bruta disminuyó del 41,3 \% en la administración López Michelsen y al 38,6\% en el Gobierno de Santos Calderón. Por tanto, de manera inversa, el consumo intermedio ${ }^{4}$ aumentó del
$58,7 \%$ en el lapso 1975-1978 al 61,4 $\%$ en 2011-2014, pues si bien estas cifras no aparecen en la Tabla 1, se deducen por simple diferencia. En consecuencia, puede decirse que el consumo intermedio representó durante todo el lapso estudiado cerca del $60 \%$ de la producción bruta 5 , lo que indicaría que más de la mitad de las actividades o insumos que forman parte del costo final de los productos industriales proviene

$3 \quad$ Según el DANE, "el valor de la producción bruta es igual al «Valor de todos los productos del establecimiento» más los «Ingresos por subcontratación industrial realizados para otros», más el «Valor de la energía eléctrica vendida», más el «Valor de los ingresos causados por CERT», más el «Valor de las existencias de los productos en proceso de fabricación al finalizar el año», menos el «Valor de los productos en proceso de fabricación al iniciar el año», más el valor de otros ingresos operacionales, tales como los generados por el alquiler de bienes producidos y la instalación, mantenimiento y reparación de productos fabricados por el establecimiento". (DANE, 2015, p. 40)

4 Según el DANE, corresponde al "valor de todos los insumos utilizados por el establecimiento en el proceso productivo. Incluye el valor de las siguientes variables: consumo de materias primas, materiales y empaques valorados a precio de adquisición (sin incluir los impuestos indirectos), energía eléctrica comprada, obsequios y muestras gratis, accesorios y repuestos consumidos, otros energéticos consumidos, servicios públicos (agua, correo, teléfono, etc.), gastos de subcontratación industrial, gastos por labores industriales realizadas por trabajadores a domicilio, honorarios y servicios técnicos, gastos por servicios de mantenimiento y reparaciones, seguros (excepto los de prestaciones sociales), arrendamiento de los bienes inmuebles y arrendamiento de los bienes muebles". (DANE, 2015, p. 40)

5 EI DANE denomina esta relación porcentual como "el coeficiente técnico insumo-producto", el que, como ejemplo, para el año 2013 fue de $61,3 \%$, confirmando que este coeficiente ha cambiado poco en el lapso estudiado. (DANE, 2015 , p. 2) 
de otros sectores, confirmando que la industria, por su naturaleza, es una actividad transformadora de insumos provenientes del sector primario, o del mismo sector secundario, o consumidora de diferentes servicios procedentes del sector terciario, algunos de los cuales antes se generaban en las mismas empresas industriales.

Esta situación, per se, no es negativa, pues puede permitir incorporar productos y servicios elaborados por empresas especializadas, lo que supone tecnología más actualizada y costos más bajos. Así, por ejemplo, para el año 2013 la Encuesta Anual Manufacturera encontró que de una producción bruta de 203,8 billones de pesos corrientes, $\$ 125$ billones correspondieron a consumo intermedio, distribuido así: consumo de materias primas, materiales y empaques por $\$ 110,2$ billones $(88,2 \%)$; pagos por trabajos de carácter industrial realizados por terceros (incluyendo los trabajadores a domicilio) $\$ 2,8$ billones (2,2\%); valor causado por las empresas que suministran al establecimiento personal temporal vinculado a producción (profesionales, técnicos, tecnólogos, obreros y operarios) $\$ 1,7$ billones $(1,4 \%)$ y el resto, $\$ 10,3$ billones, el 8,2 \%, corresponde a otros costos industriales (DANE, 2015, pp. 22-23). Este ejemplo comprueba como el 3,6 \% del consumo intermedio, $\$ 4,5$ billones, corresponde al pago de trabajos que, en las condiciones anteriores, cuando los trabajadores estaban vinculados de manera directa a las empresas industriales, se hubiese considerado como valor agregado, lo cual explica, en parte, la pérdida de participación del PIB industrial en el PIB total de la economía; pues el valor agregado subestima la importancia verdadera de la industria, al ignorar la porción de la cadena productiva que está por fuera de las firmas industriales y que además ha crecido durante las últimas décadas por cuenta de los procesos de tercerización.

\section{CAMBIOS EN LA COMPOSICIÓN DEL VALOR AGREGADO INDUSTRIAL}

En cuanto a la composición del valor agregado, el cambio es más drástico; mientras la remuneración total recibida por los trabajadores (excluidos los trabajadores temporales indirectos, como se aclarará más adelante) solo tuvo una variación algo superior a $33 \%$ en los diez gobiernos analizados en este estudio, el valor agregado -que incluye las ganancias empresariales- tuvo un incremento muy superior, de más del $110 \%$. Esto se refleja en el hecho de que la participación de la remuneración en el valor agregado -en términos de economía política marxista, la participación del trabajo en la nueva riqueza ${ }^{6}$ creada-disminuyó de un poco

\footnotetext{
$\overline{6} \quad$ La mayoría de las corrientes del pensamiento económico entienden por riqueza la acumulación de bienes o dinero, pero nos parece más apropiada la concepción prístina de Adam Smith. En su crítica a los fisiócratas dice que "(...) la riqueza de las naciones no consiste en las riquezas del dinero que no se pueden consumir sino en los bienes de consumo [que en la contabilidad moderna incluye bienes y servicios para el consumo personal y bienes de capital] que se reproducen anualmente gracias al trabajo de la sociedad; (...)". Idea que ya está en el párrafo inicial de su libro. (Smith, 1994, pp. 658 y 27)
} 
más del $31 \%$ en 1975-1978 a menos del $20 \%$ en 2011-2014, como puede verse en la Tabla 1; de manera correlativa, la participación del excedente bruto -que representa la participación de diversas formas del capital y otros agentes no asalariados- aumentó de casi $70 \%$ en 1975-1978 a más de $80 \%$ en 20112014. Diciéndolo de otra manera, en el cuatrienio 2011-2014 cuatro quintas partes de la riqueza creada quedó en el bolsillo de los capitalistas - en su expresión más amplia- y solo una quinta parte en manos de los trabajadores ${ }^{7}$. Nótese la diferencia tan grande que existe en la proporción que representa el excedente bruto en comparación con el dato que se cita de Piketty en párrafo anterior, aunque la composición de los agregados pueden tener alguna diferencia: 33 \% en Francia en 2010 y $80 \%$ en Colombia en 20112014; en Colombia, el excedente bruto representa, respecto al valor agregado, una cifra que es más del doble que en Francia, en donde significa una tercera parte. Cabe aclarar que el trabajo de Piketty se basa en el conjunto de la economía francesa, mientras que aquí los autores han analizado el mismo fenómeno tan solo en la industria colombiana; no obstante, la diferencia impresiona ${ }^{8}$.
En el caso de la relaciones entre los trabajadores y los dueños de los medios de producción -que en economía política marxista también se llama la relación trabajo-capital-, la situación en la industria manufacturera colombiana durante el transcurso de la segunda parte del siglo $20^{9} \mathrm{y}$ principios del siglo 21 fue muy cambiante, teniendo su punto de inflexión hacia finales de los años ochenta y principios de los noventa, cuando entró en vigencia una reforma laboral que flexibilizó las condiciones de contratación y despido de los trabajadores. En la Tabla 2, preparada con base en cifras absolutas de la Tabla 1, se observa que en el curso de esos diez gobiernos la remuneración promedio por cuatrienio y trabajador remunerado aumentó hasta la segunda parte de la década de los noventa, pues pasó de \$70,4 millones en 1975-1978 a \$94,8 millones en 19951998, en pesos constantes de 2005, lo que implicó un incremento de casi el $35 \%$ en 24 años, seis gobiernos; en los cuatro cuatrienios siguientes disminuye de manera progresiva la remuneración per cápita hasta $\$ 80,7$ millones en la administración Santos Calderón, o sea se perdió un $15 \%$; en todo el lapso 19752014, 40 años, la remuneración promedio

$7 \quad$ Visto en valores corrientes, esta proporción se mantiene. Según la EAM 2013, la remuneración total alcanzó $\$ 15,9$ billones y el valor agregado llegó a $\$ 78,8$ billones, esto es, 20,2 \%. (DANE, 2015, pp. 5-6)

8 Sin embargo, al analizar en la investigación más extensa lo ocurrido entre 2002 y 2014 en otros sectores de la economía colombiana, se encontró que en las actividades financieras y similares el porcentaje del valor agregado que corresponde a la remuneración al trabajo oscila entre el $23 \%$ y el $25 \%$, y en el comercio, reparaciones de vehículos, hoteles y restaurantes esa proporción oscila alrededor del $40 \%$. Si se tiene en cuenta que para 2014 estos tres sectores representaban más del 40 \% del PIB total, la comparación con el caso francés ya es más válida.

$9 \quad$ Aunque las Academias de la Lengua Española recomiendan escribir los siglos con números romanos, los autores prefieren hacerlo con números arábigos, como se acostumbra ya en otros idiomas, pues nos parece que la numeración románica es obsoleta y difícil de entender, además de que en la práctica ya casi no se enseña en el sistema educativo. 
solo mejoró en casi $15 \%$, mientras que el excedente bruto por trabajador ocupado aumentó en más del $70 \%$, pues pasó de casi \$150 millones en 1975-78 a casi \$260 millones en 2011-2014, en pesos de 2005. Estas cifras, por sí solas, evidencian la inequidad en la distribución de la riqueza creada.

Tabla 2. Industria 1975-2014: coeficientes per cápita en variables seleccionadas

\begin{tabular}{|l|c|c|c|c|}
\hline \multicolumn{1}{|c|}{ GOBIERNOS } & $\begin{array}{c}\text { RT pc } \\
\text { mn\$ }\end{array}$ & $\begin{array}{c}\text { PB pc } \\
\text { mn\$ }\end{array}$ & $\begin{array}{c}\text { VA pc } \\
\text { mn\$ }\end{array}$ & $\begin{array}{c}\text { EB pc } \\
\text { mn\$ }\end{array}$ \\
\hline Alfonso López Michelsen (1975-1978) & 70,4 & 526,6 & 217,5 & 149,7 \\
\hline Julio César Turbay Ayala (1979-1982) & 80,0 & 567,3 & 242,1 & 163,3 \\
\hline Belisario Betancur C. (1983-1986) & 89,5 & 652,9 & 262,0 & 173,9 \\
\hline Virgilio Barco Vargas (1987-1990) & 84,2 & 773,6 & 297,9 & 215,1 \\
\hline César Gaviria Trujillo (1991-1994) & 89,5 & 629,2 & 257,3 & 179,2 \\
\hline Ernesto Samper Pisano (1995-1998) & 94,8 & 598,5 & 269,8 & 190,8 \\
\hline Andrés Pastrana Arango (1999-2002) & 89,9 & 669,0 & 295,3 & 220,3 \\
\hline Álvaro Uribe Vélez (2003-2006) & 84,6 & 754,2 & 324,1 & 260,9 \\
\hline Álvaro Uribe Vélez (2007-2010) & 84,7 & 753,7 & 330,9 & 267,8 \\
\hline Juan Manuel Santos (2011-2014) & 80,7 & 838,7 & 323,4 & 259,3 \\
\hline \% de variación 2011-14/1975-78 & $14,7 \%$ & $59,3 \%$ & $48,6 \%$ & $73,3 \%$ \\
\hline
\end{tabular}

Fuente: Encuestas anuales manufactureras -EAM- del DANE, cálculos de los autores

RT pc $=$ Remuneración promedio por trabajardor ocupado remunerado

$\mathrm{PB}$ pc $=$ Pruducción Bruta por trabajador ocupado

$\mathrm{VA} \mathrm{pc}=$ Valor Agregado por trabajador ocupado

$\mathrm{EB}$ pc $=$ Excedente Bruto por trabajador ocupado

mn\$ = Millones de pesos de 2005

DISMINUCIÓN EN EL VALOR RELATIVO DEL TRABAJO Y AUMENTO EN LA PRODUCTIVIDAD LABORAL, CON PRECARIEDAD EN EL EMPLEO

Al mismo tiempo, la producción bruta por trabajador ocupado, o producción bruta per cápita $(\mathrm{PB} \mathrm{pc})$, aumentó a mayor ritmo que el valor agregado por trabajador ocupado, o valor agregado per cápita (VA pc), ya que mientras la primera tuvo una variación de casi el $60 \%$ en los 40 años, en la segunda la variación fue inferior al 50 \%, según se aprecia en la Tabla 2, diferencia que puede tener como hipótesis explicativa un incremento calificado del consumo intermedio, una parte por medio de la "tercerización" o "outsourcing", según la expresión en inglés, así como por cambios tecnológicos en los procesos de producción. Hay que aclarar que para el cálculo de los coeficientes (PB pc) y (VA pc), que se muestran en la Tabla 2, se tuvo en cuenta el total de la población ocupada (PO), que aparece en la Tabla 3 , guarismo que incorpora la población ocupada remunerada y no remunerada y los trabajadores contratados bajo otras modalidades.

Es de destacar la diferencia tan notoria entre el crecimiento de la población total ocupada y la población ocupada 
remunerada (trabajadores con contrato a término indefinido y trabajadores temporales contratados por las empresas industriales), pues mientras los primeros aumentaron en casi $42 \%$ durante los diez gobiernos, los segundos solo lo hicieron en menos del $17 \%$ (véase la Tabla 3). Es decir, fue muy bajo el crecimiento del empleo en la industria, pues en tasa geométrica la ocupación total lo hizo al $1 \%$ anual, mientras la ocupación remunerada directa, un empleo con mejores condiciones, lo hizo a un ritmo que fue la mitad: $0,5 \%$ anual. De modo que la evolución del empleo industrial muestra dos cosas, un aumento de la flexibilización en la contratación y bajos incrementos en el empleo, simultáneamente con un incremento en la productividad laboral, si se toma como medida de la productividad, así sea muy burda, los coeficientes (PB pc) y (VA pc), ya mencionados. Diciéndolo de otra manera, mientras el empleo total industrial creció a un ritmo que es inferior a la mitad del incremento de la producción, la población ocupada remunerada lo hizo solo en un poco más de una quinta parte. O sea, la situación colombiana es similar a lo que ocurre en las demás economías capitalistas: cada vez se utilizan menos trabajadores y cada vez en condiciones más precarias ${ }^{10}$, para producir más bienes industriales. La precariedad en el empleo se hace evidente con las nuevas formas de contratación, que en algunos casos, generan inestabilidad en los trabajadores y débiles condiciones en relación con la empresa o con organizaciones sindicales. Así, la flexibilización del mercado laboral se convierte en un nuevo estado de fuerzas en la relación capital-trabajo, que se expresa en una mayor capacidad de explotación del trabajo por parte del capital.

$\overline{10}$ Los autores encuentran que las cifras de empleo que muestra la industria reflejan lo que la Organización Internacional del Trabajo -OIT- señala como trabajo precario, considerado como aquel "trabajo que se realiza en la economía formal e informal y que se caracteriza por niveles variables y grados de particularidades objetivas (situación legal) y subjetivas (sensación) de incertidumbre e inseguridad. Si bien un trabajo precario puede tener diversas facetas, se lo suele definir por la incertidumbre que acarrea en cuanto a la duración del empleo, la presencia de varios posibles empleadores, una relación de trabajo encubierta o ambigua, la imposibilidad de gozar de la protección social y los beneficios que por lo general se asocian con el empleo, un salario bajo y obstáculos considerables tanto legales como prácticos para afiliarse a un sindicato y negociar colectivamente". (OIT, 2012) 
Tabla 3. Industria 1975-2014: población ocupada total y remunerada

\begin{tabular}{|c|c|c|c|c|c|c|c|c|}
\hline \multirow[b]{2}{*}{ G O B I E R N O S } & \multirow[b]{2}{*}{ Total PO } & \multicolumn{5}{|c|}{ Población Ocupada Remunerada -POR- } & \multirow[b]{2}{*}{$\begin{array}{c}\text { POR/ } \\
\text { PO }\end{array}$} & \multirow{2}{*}{\begin{tabular}{|c|} 
Tempo- \\
ral \\
Indirec \\
to/PO
\end{tabular}} \\
\hline & & Total & $\begin{array}{c}\text { Perma- } \\
\text { nente }\end{array}$ & $\begin{array}{c}\% \text { del } \\
\text { total }\end{array}$ & \begin{tabular}{|c|}
$\begin{array}{c}\text { Temporal } \\
\text { directo }\end{array}$ \\
\end{tabular} & $\begin{array}{c}\% \text { del } \\
\text { total }\end{array}$ & & \\
\hline Alfonso López Michelsen (1975-1978) & 478,618 & 461,413 & 461,413 & $100,0 \%$ & 0 & $0,0 \%$ & $96,4 \%$ & $3,6 \%$ \\
\hline Julio César Turbay Ayala (1979-1982) & 505,752 & 498,074 & 498,074 & $100.0 \%$ & 0 & $0,0 \%$ & $98,5 \%$ & $1,5 \%$ \\
\hline Belisario Betancur C. (1983-1986) & 460,117 & 453,095 & 453,095 & $100,0 \%$ & 0 & $0,0 \%$ & $98,5 \%$ & $1,5 \%$ \\
\hline Virgilio Barco Vargas (1987-1990) & 487,249 & 479,690 & 479,690 & $100,0 \%$ & 0 & $0,0 \%$ & $98,4 \%$ & $1,6 \%$ \\
\hline César Gaviria Trujillo (1991-1994) & 610,251 & 561,133 & 524,193 & $93,4 \%$ & 36,940 & $6,6 \%$ & $92,0 \%$ & $8,0 \%$ \\
\hline Ernesto Samper Pisano (1995-1998) & 625,427 & 547,280 & 511,943 & $93,5 \%$ & 35,336 & $6,5 \%$ & $87,5 \%$ & $12,5 \%$ \\
\hline Andrés Pastrana Arango (1999-2002) & 531,806 & 443,831 & 368,306 & $83,0 \%$ & 75,526 & $17,0 \%$ & $83,5 \%$ & $16,5 \%$ \\
\hline Álvaro Uribe Vélez (2003-2006) & 579,116 & 432,486 & 328,829 & $76,0 \%$ & 103,657 & $24,0 \%$ & $74,7 \%$ & $25,3 \%$ \\
\hline Álvaro Uribe Vélez (2007-2010) & 649,369 & 484,433 & 365,016 & $75,3 \%$ & 119,417 & $24,7 \%$ & $74,6 \%$ & $25,4 \%$ \\
\hline Juan Manuel Santos (2011-2014) & 679,022 & 538,700 & 392,475 & $72,9 \%$ & 146,225 & $27,1 \%$ & $79,3 \%$ & $20,7 \%$ \\
\hline \% de variación 2011-14/1975-78 & $41,9 \%$ & $16,8 \%$ & $-14,9 \%$ & & & & & \\
\hline TAG periodo 1976-2014 (39 años) & $1,0 \%$ & $0,5 \%$ & & & & & & \\
\hline
\end{tabular}

Fuente: DANE, Encuestas anuales manufactureras, cálculos de los autores.

$\mathrm{PO}=$ Población Ocupada (Número de trabajadores promedio por cuatrienio)

$\mathrm{POR}=$ Población Ocupada Remunerada (Número de trabajadores promedio por cuatrienio)

Permanente $=$ Trabajadores con contrato de trabajo a término inmediato

Temporal $=$ Trabajadores con contrato de trabajo a término fijo

Indirecto $=$ Trabajadores contratados a término fijo por medio de empresas dedicadas al suministro de personal

Otros trabajos han encontrado resultados similares. Un análisis econométrico de los profesores Méndez y Hernández (2014, pp. 344, 346-347) sobre "los datos de producción, el empleo y los salarios pagados en el sector manufacturero en 24 departamentos de Colombia, durante 1992-2010”, y que buscaba la relación a largo plazo entre los salarios reales y la productividad laboral en el sector manufacturero, encontró que la "evolución del salario real promedio", entendido como la "media aritmética de la variable para los 24 departamentos de la muestra", (...) "presenta una tendencia decreciente hasta el año 2008, que implicó una pérdida de cerca del $20 \%$ del salario real promedio, y una posterior recuperación de aproximadamente el $8 \%$ del salario real”, lo que supone una disminución efectiva cercana al $12 \%$ durante los 18 años. Al mismo tiempo encontraron una tendencia creciente en la evolución de la productividad promedio, la que, según una gráfica que acompaña su trabajo, creció en cerca de $60 \%$ durante el mismo lapso. A continuación señalan que "la parte del valor de la producción de la que se apropian los trabajadores [nota de JS-C y CPP: lo que coincide, en términos generales, con lo que en este artículo se ha llamado la participación del trabajo en la riqueza creada en la industria, o valor agregado] cayó en cerca de un 50\%, así que la caída en el salario real está asociada a la pérdida de participación de los trabajadores en el valor de la producción. Esto evidencia un conflicto en la distribución de las ganancias de la productividad; se generó una brecha salarial negativa (porque el salario 
real cae mientras que la productividad laboral aumenta) que pone en riesgo a la economía de enfrentar una restricción de demanda", dada la previsible disminución en el consumo de los hogares de los trabajadores.

En otro análisis similar, el profesor (Samper, 2016, p. 10-11) señala que "Al examinar en forma global la productividad de la industria entre 1990 y 2012, se registra una tasa promedio de crecimiento anual de $3,68 \%$, es decir, un aumento frente a los años 70-89 cuando fue del 3\%. En contraste, el salario real evolucionó a un ritmo promedio de $1,65 \%$, cuando en el periodo anterior superó a la productividad al llegar a 3,58\%. Estos resultados indican que los trabajadores aportaron mayores tasas de crecimiento de la productividad a costa de una reducción en sus salarios reales, para un diferencial por debajo de la productividad de $2,03 \%$ [nota de JS-C y CPP: en realidad debería decirse de 2,03 puntos porcentuales, pues es el resultado de 3,68 menos 1,65], mientras en el lapso anterior esta diferencia superaba a la productividad en $0,58 \%$ [o 0,58 puntos porcentuales, como resultado de 3,0 menos 3,58]". Según el profesor Samper, se puede inferir que hubo un aumento de las utilidades, sin correspondencia alguna con los salarios, pues estos no crecieron al mismo ritmo de la productividad, buena parte como resultado de algunas leyes que introdujeron cambios en el mercado laboral favorables a los empresarios.
Como se aprecia en las dos últimas columnas de la Tabla 3, el peso de los trabajadores temporales indirectos empezó a aumentar en la década de los noventa a raíz de los cambios legales que facilitaron este tipo de contratación; mientras hasta el Gobierno de Barco Vargas la población ocupada remunerada representaba más del $98 \%$ de la población ocupada, es decir, en la práctica no existía la temporalidad en la industria, en Gaviria Trujillo esa relación baja al $92 \%$ y sigue disminuyendo en los siguientes gobiernos, hasta menos del $75 \%$ en las dos administraciones Uribe Vélez, para subir un poco en la primera de Santos Calderón al $79 \%$. Es decir, entre el $20 \%$ y el $25 \%$ de los trabajadores industriales son contratados como temporales indirectos a través de empresas dedicadas a esta labor ${ }^{11}$.

Pero la situación para los trabajadores, en general, es más crítica, pues una porción creciente de la población ocupada remunerada corresponde a temporales directos, puesto que su cantidad aumentó de un poco menos de 37.000 trabajadores, como promedio en el cuatrienio de Gaviria Trujillo (primer Gobierno en que empezó a utilizarse esta categoría en las estadísticas laborales), hasta más de 146.000 trabajadores en la primera administración de Santos Calderón, como se aprecia en la misma Tabla 3; ya en los últimos gobiernos se acerca o pasa del $25 \%$, esto es, alrededor de uno

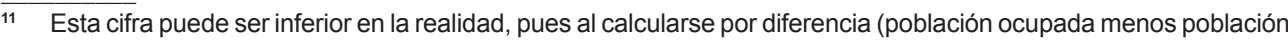
ocupada remunerada), quedan incluidos los propietarios y familiares sin remuneración, aunque éstos últimos también pueden estar en condiciones de precariedad. 
de cada cuatro trabajadores ocupados remunerados es temporal directo, esto es, contratado por las mismas empresas industriales.

O sea, menos del $60 \%$ de los trabajadores industriales cuenta hoy con contrato de trabajo a término indefinido: en términos exactos, 392.475 trabajadores sobre un total de 679.022, como promedio cuatrienal en la primera administración de Santos Calderón. En corroboración de lo anterior, puede recordarse que un Informe de la Federación de Aseguradores de Colombia -FASECOLDA- destaca que para mediados de la segunda década del siglo 21 el 62,7 \% de los trabajadores de la industria manufacturera corresponde a trabajadores formales y el 37,3 \% a informales; el extremo de la informalidad está en comercio, hoteles y restaurantes con el 65,8 \%, y de la formalidad en suministro de electricidad, gas y agua con el 96,8 \% (El Tiempo, 2016, p. 1). Estas cifras comprueban, por otra vía, la situación precaria de los trabajadores en la relación trabajo-capital, lo que en gran medida afecta las condiciones generales del desarrollo humano.

Lo visto en párrafos anteriores permite suponer que desde mediados de los años noventa los empresarios tuvieron mayor poder de negociación en el proceso de fijar los salarios y las prestaciones sociales, lo que indicaría, de otra manera, que una serie de modificaciones en la legislación laboral ha facilitado una acción predominante del empresariado en el mercado laboral, aunado, quizá, a una creciente debilidad del movimiento sindical. Pero hay que insistir que es irónico que esto haya ocurrido, pues durante este mismo tiempo los trabajadores han hecho un gran esfuerzo para aumentar su escolaridad, mejorar sus habilidades de trabajo y elevar su expectativa de vida, lo cual redunda en una mayor permanencia en el mercado laboral, con la correspondiente acumulación de conocimiento y experiencia, como las estadísticas sobre desarrollo humano lo comprueban, lo que supone una apreciable "valorización” del trabajo humano, o del “capital humano", como dicen algunos autores (Tinoco \& Soler, 2011), con expresión no muy apropiada. Sin duda, hay una creciente divergencia, difícil de cuantificar, entre el valor social que adquiere el trabajo, sobre todo por lo ya señalado de incremento en la escolaridad y la mayor experiencia laboral, y el precio real que se le reconoce, como remuneración total o participación en el valor agregado. (Silva-Colmenares, 2015)

Sobre el excesivo excedente que se genera en Colombia, el académico Gabriel Misas plantea lo siguiente:

[...] la configuración de estructuras oligopólicas, al amparo de sólidas barreras que impedían la entrada de nuevos competidores y de altos niveles de protección efectiva, ha permitido que se generara un excedente considerable, mediante el manejo de los márgenes de utilidad (mark-up). Estos montos, que superan con creces los requerimientos de nuevas inversiones para satisfacer 
el crecimiento de la demanda en sus respectivas ramas industriales, han dado origen a un acopio de recursos excedentes, que deben ser colocados en otras actividades de la economía. (Misas, 1993, p. 10).

Según Misas, el "grueso de los mismos fue dedicado a la compra de activos financieros y de valores de refugio (dólares y bienes inmobiliarios, entre otros), así como al consumo suntuario. [...]". Y como explicación para esa desviación aclara, con base en P. S. Labini, que "en condiciones de oligopolio, la expansión de la capacidad productiva depende del comportamiento de la demanda y no de los fondos disponibles de las empresas. (Misas, 1993, p. 10).

Los autores de este artículo plantean una hipótesis diferente sobre el uso de parte de este excedente excesivo: a partir del inicio de la década de los noventa del siglo pasado, los principales grupos financieros y conglomerados empresariales del país dedicaron una porción considerable de esos excedentes excesivos a la inversión directa en el extranjero, sobre todo para la compra de empresas ya existentes, con tradición y amplia cobertura, en lo que se ha llamado el proceso de transnacionalización del gran capital colombiano (SilvaColmenares \& Padilla-Pardo, 2015), que no niega que en décadas anteriores también se hubiese dado ese fenómeno, pero con menor intensidad, como de manera indirecta lo comprueban en libro ya mencionado.

\section{CRECIMIENTO DE LA DESIGUAL- DAD EN EL MARCO DE LA TRANS- FORMACIÓN INDUSTRIAL}

Para complicar este panorama, esa inequidad distributiva ocurre al tiempo que pierde peso relativo la industria en el conjunto de la economía colombiana. Como se observa en la Tabla 4, el valor agregado industrial, como proporción del PIB total, disminuyó del 17,4 \% en 1978, último año del Gobierno López Michelsen, al $13,8 \%$ en 1994, al final del Gobierno Gaviria Trujillo, cuando se supone ya se había acelerado la apertura económica, y al $11,1 \%$ en 2014, último año de la primera administración de Santos Calderón, pero durante los nueve gobiernos que cubre este lapso el incremento del PIB industrial mostró una tasa anual acumulativa del 2,48 $\%$, que si bien es inferior al crecimiento del PIB total (3,78\% anual), es superior al incremento de la población, que tuvo una tasa anual acumulativa de 1,75\% durante el mismo lapso; es decir, la disponibilidad de bienes industriales aumentó durante los 36 años a una tasa anual acumulativa cercana al 0,8 \%. Parte del crecimiento perdido en la industrial puede haberse transferido a sectores como comercio, que incluye algunas actividades de reparaciones, transporte y almacenamiento o servicios personales, en donde se realizan trabajos que antes se hacían en las empresas industriales, y formaban parte de su valor agregado, y ahora se contabilizan como consumo intermedio. Como se observa en la Tabla 4, estos sectores crecieron a tasas acumulativas cercanas o superiores al $4 \%$ anual, durante ese lapso. 
Tabla 4. Valor agregado por ramas de actividad económica 1978 - 1994 - 2014. Billones de pesos, a precios constantes de 2005 por encadenamiento

\begin{tabular}{|l|r|r|r|r|r|r|r|}
\hline & $\mathbf{1 9 7 8}$ & $\begin{array}{c}\text { Partici- } \\
\text { pación en } \\
\text { el PIB } \\
\text { Total }\end{array}$ & $\mathbf{1 9 9 4}$ & $\begin{array}{c}\text { Partici- } \\
\text { pación en } \\
\text { el PIB } \\
\text { total }\end{array}$ & $\begin{array}{c}\text { Partici- } \\
\text { 2014 }\end{array}$ & $\begin{array}{c}\text { TAG } \\
\text { el PIB } \\
\text { Total }\end{array}$ & $\begin{array}{c}\text { T978- } \\
\mathbf{2 0 1 4}\end{array}$ \\
\hline Agricultura, ganadería, caza, silvicultura y pesca & 13,5 & $9,5 \%$ & 21,9 & $8,3 \%$ & 31,6 & $6,1 \%$ & $2,51 \%$ \\
\hline Explotación de minas y canteras & 2,2 & $1,5 \%$ & 14,5 & $5,5 \%$ & 37,8 & $7,3 \%$ & $7,75 \%$ \\
\hline Industrias manufactureras & 24,7 & $17,4 \%$ & 36,4 & $13,8 \%$ & 57,2 & $11,1 \%$ & $2,48 \%$ \\
\hline Suministro de electricidad, gas y agua & 5,2 & $3,7 \%$ & 10,9 & $4,1 \%$ & 17,9 & $3,5 \%$ & $3,62 \%$ \\
\hline Construcción & 9,5 & $6,7 \%$ & 21,0 & $8,0 \%$ & 37,0 & $7,2 \%$ & $3,59 \%$ \\
\hline Comercio & 14,6 & $10,3 \%$ & 24,2 & $9,2 \%$ & 61,8 & $12,0 \%$ & $4,17 \%$ \\
\hline Transporte, almacenamiento y comunicaciones & 8,7 & $6,1 \%$ & 15,1 & $5,7 \%$ & 37,5 & $7,3 \%$ & $4,29 \%$ \\
\hline $\begin{array}{l}\text { Establecimientos financieros, seguros, actividades } \\
\text { inmobiliarias y servicios a las empresas }\end{array}$ & 25,6 & $18,0 \%$ & 53,3 & $20,2 \%$ & 101,7 & $19,7 \%$ & $3,98 \%$ \\
\hline $\begin{array}{l}\text { Actividades de servcios sociales, comunales y } \\
\text { personales, hoteles y restaurantes }\end{array}$ & 19,8 & $13,9 \%$ & 43,0 & $16,3 \%$ & 79,5 & $15,4 \%$ & $3,96 \%$ \\
\hline Impuestos menos subvenciones sobre los productos & 18,2 & $12,8 \%$ & 23,5 & $8,9 \%$ & 54,6 & $10,6 \%$ & $4,51 \%$ \\
\hline Producto Interno Bruto & 142,0 & $100,00 \%$ & 263,6 & $100,00 \%$ & 516,6 & $100,00 \%$ & $3,78 \%$ \\
\hline Población estimada (millones de personas) & 25,6 & & 36,9 & & 47,7 & & $1,75 \%$ \\
\hline
\end{tabular}

Fuente: DANE - Dirección de Síntesis y Cuentas Nacionales

* Este rubro se calculó como la diferencia entre el total del PIB y la sumatoria de todas las actividades económicas, para efecto de totales

Pr: Proyectado

TAG = Tasa Anual Geométrica o Acumulativa, para el periodo indicado

Teniendo en cuenta la pérdida de participación de la industria en el PIB total, algunos analistas plantean que en Colombia ha ocurrido un creciente “proceso de desindustrialización”, pero los datos macroeconómicos no lo evidencian tan claro, ya que las cifras absolutas del PIB, la producción bruta y el consumo intermedio de la industria no muestran una disminución tan apreciable como para hablar de “desindustrialización”. Por eso, como dice uno de los autores de este artículo, en una publicación al respecto, "una cosa es que la industria haya perdido peso relativo en el total del PIB [...] y otra cuestión distinta es que haya perdido importancia, como puede dar a entender la palabra desindustrialización”. Y después de citar cifras parecidas a las anteriores, dice que "Visto así el fenómeno ocurrido -y no sólo en Colombia, sino en muchos países del mundo- creemos que se está utilizando con un significado equivocado la categoría desindustrialización, palabra compuesta resultante de anteponer el prefijo des al sustantivo industrialización". Y respecto a tal prefijo recuerda que la Nueva Gramática de las Academias de la Lengua Española dice que "Con este prefijo se crean numerosos nombres derivados que denotan acciones, situaciones o propiedades opuestas a las expresadas por sus bases nominales, como desacuerdo, desdicha, deshonor, despropósito o desvergüenza. En otros sustantivos, el prefijo se interpreta con 
sentido privativo: desaseo, desempleo, desmesura, desobediencia, desorden. [...]" (Silva-Colmenares, 2014, p.112).

Por tanto, precisa más adelante:

“[...] en el fenómeno quenos interesa, la categoría desindustrialización no puede significar lo opuesto a industrialización, o tener un sentido privativo, [...] pues la industria no ha desaparecido ni está en proceso de desaparecer, ya que lo que ocurre es que está cambiando de contenido o incluso de esencia, dadas las transformaciones sustanciales por las que pasa [...]. Estos cambios la han llevado a perder peso relativo en el agregado nacional, sin que haya perdido importancia. Incluso mejorías significativas en la actividad industrial, como por ejemplo la elevación de la productividad (más unidades de producto por unidad de tiempo o por persona ocupada) o innovaciones en proceso y materiales (como la sustitución de minerales tradicionales pesados por nuevas aleaciones livianas), pueden llevar a reducciones importantes en costos unitarios, lo que hace que disminuya el monto dinerario y aumente el volumen producido, afectándose su peso relativo en el agregado nacional. [...]"' (SilvaColmenares, 2014, pp. 112-113).

En cambio, sí hay que hablar más sobre la "cuarta revolución industrial” y sus eventuales efectos en una economía como la colombiana. Como se señala en comentario sobre un libro con este título de Klaus Schwab, presidente del Foro Económico Mundial: “[...] esta cuarta revolución industrial se sustenta en un cambio digital que comenzó a registrarse desde mediados del siglo pasado y que tiene como particularidad la fusión de tecnologías que están borrando los límites entre las esferas físicas, digitales y biológicas y que tiene un efecto transversal a todas las disciplinas, las economías e industrias" (Dinero, 2016, p.18). Como dice el mismo Schwab en un artículo sobre el tema:

Con todo lo notables que sean, las nuevas tecnologías son herramientas creadas por personas para personas. Debemos recordar esto y asegurarnos de que la innovación siga poniendo a la gente en primer lugar. Tengo la convicción de que la nueva era tecnológica, si se encara responsablemente, podría catalizar un renacimiento cultural que nutra la noción de una civilización global. Pero también puede atentar contra las fuentes que dan sentido a la humanidad (trabajo, comunidad, familia e identidad). La decisión es nuestra. (Schwab, 2016, p.5).

En complemento, como se lee en un artículo publicado por el Centro Latino Americano de Ecología Social -CLAESde Uruguay:

A lo largo de la historia, las tecnologías han impactado en el mundo 
del trabajo, creando y destruyendo puestos, modificando los procesos de producción, transformando las relaciones sociales y con ellas nuestras propias vidas. Estamos ahora frente a una nueva transformación, una «cuarta revolución» industrial que involucra la integración de robots, autómatas, inteligencia artificial, nanotecnologías, biotecnologías, entre otras, en los procesos de producción, [...] Al margen del mayor o menor énfasis en las previsiones, lo cierto es que la presencia de la robótica y la automatización en el mundo del trabajo son cada vez mayores y la discusión en torno a su incidencia y sus impactos sociales estará cada vez más presente en los medios. Esa discusión no es nueva, pero se reformula incorporando nuevos elementos en la medida en que la ciencia y la tecnología van desarrollando dispositivos capaces de realizar más y mejores tareas. [...] Es que las viejas fábricas se reciclan hacia estructuras automatizadas, y las nuevas inversiones ya parten desde esa base. Todo esto hace que la discusión de los efectos de la robotización sobre el mercado de trabajo también deba ser contemplada en nuestro continente. (Gutiérrez, 2016).

En relación con lo anterior, el Informe sobre Desarrollo Humano de 2015, dedicado al tema Trabajo al servicio del desarrollo humano, afirma:

El contexto del trabajo está sufriendo cambios que afectan al desarrollo humano. La globalización y las revoluciones tecnológicas, en particular la revolución digital, impulsan la transformación del trabajo. La globalización ha favorecido la interdependencia mundial y ha tenido importantes repercusiones en los patrones de comercio, la inversión, el crecimiento y la creación y destrucción de empleo, así como en las redes de trabajo creativo y voluntariado. Parece que estamos viviendo nuevas y aceleradas revoluciones tecnológicas. (Programa de las Naciones Unidas para el Desarrollo, 2016, p. 7).

$Y$ en referencia a las empresas multinacionales ${ }^{12}$, que en el caso de Colombia pueden ser tanto criollas como extranjeras, el Informe del PNUD afirma más adelante:

con el fin de proporcionar flexibilidad en la producción y gestionar los costos, recurren cada vez más a una mano de obra desprotegida, utilizando una combinación de empleados con contratos de duración determinada, trabajadores eventuales, contratistas independientes, trabajadores con contratos basados en proyectos y

Los autores de este artículo prefieren llamarlas transnacionales. 
trabajadores subcontratados. La participación en las cadenas de valor ofrece a algunas personas empleos seguros y dignos, pero otras quedan relegadas a empleos más precarios (incluso en el mismo país y sector), en una especie de «dualidad del mercado laboral». (Programa de las Naciones Unidas para el Desarrollo, 2016, p. 9).

Si bien Colombia no ha entrado de lleno a la cuarta revolución industrial, el comportamiento del empleo industrial indica que mucho cambio tecnológico en la industria ha sido excluyente en relación con el trabajo humano.

Por otro lado, esto no niega que en el caso de Colombia haya que tener en cuenta aspectos colaterales que pueden haber disminuido la producción industrial, como el hecho de que muchas empresas industriales se han convertido en importadoras de bienes terminados -como ha ocurrido, por ejemplo, en las ramas de confecciones y productos químicos o en la industria automotriz y de máquinasherramientas- o que muchas que producían en Colombia para exportar, ahora son productoras en el exterior, en el marco del proceso de "transnacionalización" del gran capital colombiano ya mencionado. También valdría la pena resaltar el impacto de los cambios en la legislación comercial y de flujos de capitales durante los años noventa como parte del proceso de internacionalización de la economía colombiana, lo que no se tradujo en una verdadera apertura económica, como su- cedió en otros países, pero que determinó un nuevo escenario para las empresas nacionales y extranjeras. En ese sentido, habría que estudiar con más detalle fenómenos propios de “deformación” en la estructura industrial en capitalismos "tardíos” y de "monopolización precoz", como el colombiano.

En cuanto al impacto de la apertura económica en el comportamiento de la industria colombiana, no hay acuerdo al respecto, pues se encuentran opiniones que hablan de un efecto desastroso y otras de que no fue tan negativo o que más bien significó un reto para ciertos industriales o una oportunidad para otros. Tampoco algunas cifras confirman que el incremento de las importaciones haya sido tan dramático. Con base en cifras del Banco de la República, las importaciones de bienes y servicios, medidas en precios constantes de 1994, como proporción de la oferta total, pasó del 13,7 \% en 1958, año final del Gobierno de la Junta Militar, al 12,9 \% en 1990, año final del Gobierno de Virgilio Barco, y al 17,3 \% en 1994, año final del Gobierno Gaviria Trujillo, proporción que se mantuvo, en la práctica, hasta el año 2010, final de la segunda administración de Uribe Vélez, cuando subió al 18,6 \% (SilvaColmenares, 2013, p. 146); un incremento del $36 \%$ en su peso relativo, lo que puede ser importante, pero lo destacable es que en ningún momento de la segunda parte del siglo 20 y la primera década del siglo 21 las importaciones llegaron a ser siquiera una quinta parte de la oferta total, lo que indica la poca apertura que 
tuvo en realidad la economía colombiana durante ese lapso.

Como complemento de lo anterior, puede recordarse que en el trabajo del Grupo de Estudios del Crecimiento Económico -GRECO- del Banco de la República se muestra en la sección sobre Importaciones y actividad económica $\mathrm{y}$ en una tabla sobre Importaciones antes y después de la "apertura", que las importaciones, como proporción del PIB, en dólares, pasaron del 12,07 $\%$ en el periodo 1983-89 al 16,20 \% en 1992-97, al tiempo que las importaciones de bienes de consumo, también como proporción del PIB, pasaron del 1,06 \% al 2,89 \% en los mismos periodos; como se dice a continuación, si bien estas últimas cifras pueden verse como un aumento sustancial, "antes de la apertura tal relación era tan baja $(1,1 \%)$ que, a pesar del incremento sustancial, apenas si llega, después de la apertura, a 2,9 \% del PIB. (...)". Lo que lleva a este grupo de investigación a decir más adelante en el mismo documento que "Probablemente los aspectos más polémicos de la apertura han sido los relativos a su aplicación y efectos en el sector agropecuario (...)" (GRECO, 2002, pp. 402-403). Según la revista Dinero, que publica en cada número una serie propia de indicadores sobre la economía colombiana, las importaciones como proporción de la oferta total, medidas en dólares, pasaron del $11,8 \%$ en 1996 al $14,0 \%$ en 2014 , lo que tampoco indica una significativa apertura $^{13}$.

Así mismo, la opinión de los empresarios fue contradictoria en ese momento. Como dijo en su trabajo doctoral Nicanor Restrepo (1942-2015), quien tenía por qué saberlo, pues era un directivo prominente del grupo financiero Suramericana, con fuertes intereses en la industria, si bien la “apertura económica” implicó la eliminación de las listas de productos de prohibida importación y disminuyó de manera sustancial el arancel promedio,

Se dieron posiciones realmente enfrentadas entre sectores económicos y entre intereses regionales. Algunos empresarios, altamente beneficiarios de la protección, estuvieron totalmente en contra de la liberalización entre los que se encontraban los textileros, cultivadores de algodón y de caña de azúcar. Otros eran partidarios de la suavización del ritmo de liberalización con el propósito de darle tiempo al sistema productivo para reorganizarse tecnológicamente, reducir la rigidez de la contratación laboral y mejorar la productividad y competitividad de las empresas colombianas, entre los que figuraron ciertos productores de alimentos, químicos y farmacéuticos. Para otros era indiferente el proceso por la naturaleza de los

\footnotetext{
$\overline{13} \quad$ Una recopilación de estos indicadores se mantiene en el archivo particular de Silva-Colmenares, de donde se tomaron estos datos.
} 
intereses que representaban, por encontrarse sus empresas en el sector de bienes y productos no transables, entre los que figuraron los banqueros, aseguradores, ganaderos y cementeros; otros que se favorecían con la importación de materias primas y los comerciantes que estuvieron decididamente a favor y finalmente, algunos que podrían sin duda afectarse con la competencia internacional que les llegaría, por cuanto consideraban inminente la desaparición de la protección, decidieron buscar oportunidades, modernizar sus empresas y/o apoyarse en alianzas de capital y de cooperación con empresas internacionales, entre los cuales aparecen comerciantes, aseguradores y productores de alimentos. (Restrepo, 2011, p. 201).

Entre quienes siguieron el camino de las alianzas con empresas trasnacionales, menciona los casos de Seguros Suramericana, con Münchener RE de Alemania, Galletas Noel, con Danone de Francia, Éxito, con Casino de Francia, y Makro, con SHV de Holanda. Así mismo cita lo que le dijo en una entrevista realizada en el año 2005 el presidente de Galletas Noel, Carlos Giraldo: “... al interior de la ANDI lo que viví fue una absoluta y perfecta contradicción de opiniones...había una corriente de empresarios a favor de la apertura, una corriente moderna, una corriente de empresarios la mayoría jóvenes y había una corriente de empresarios totalmente en contra de la apertura, la mayoría empresarios maduros, muy importantes... La ANDI en todo momento fue de una posición en la que decía sí a la apertura, pero de manera gradual,...planificada y con un proceso...que permitiera la reconversión de los negocios..." (Restrepo, 2011, p. 202-203).

En resumen, se observa para Colombia un fenómeno característico del capitalismo contemporáneo: cada vez se produce más con igual o menor número de trabajadores, lo que supone no tanto una mayor explotación absoluta del trabajo humano, por la intensificación de la jornada de trabajo, sino más bien por la incorporación de ciencia y tecnología al proceso productivo, complementada con cambios que "flexibilizan" el sistema de contratación laboral, para hacer un uso "más eficiente" de la "fuerza de trabajo" comprada, pero sin que ello signifique una mejoría sustancial en el "precio total” pagado en su compra. O sea, las "revoluciones industriales" y las reformas laborales han beneficiado más al capital que al trabajo.

SE AGRAVA UNA TENDENCIA NATURAL DEL CAPITALISMO: AUMENTAR LACONCENTRACIÓN DE LA PRODUCCIÓN Y LA CENTRALIZACIÓN DEL CAPITAL

A partir de la economía política marxista, el capitalismo tiene una tendencia natural a concentrar la producción, no solo por la incorporación de ciencia y tecnología al proceso de producción y el incremento 
de la demanda-oferta por aumento de la población -lo cual es obvio-, sino por la propia centralización del capital, que elimina dueños de medios de producción. La concentración de la producción ya fue estudiada en un texto tan anterior como El Capital (publicado en 1867) por Carlos Marx (1818-1883). Con las consideraciones que supone el tiempo transcurrido, recuérdese que Marx formuló lo que llamó la ley general, absoluta, de la acumulación capitalista, de la siguiente manera: "Cuanto mayores son la riqueza social, el capital en funciones, el volumen y la intensidad de su crecimiento y mayores también, por tanto, la magnitud absoluta del proletariado y la capacidad productiva de su trabajo, tanto mayor es el ejército industrial de reserva. La fuerza de trabajo disponible se desarrolla por las mismas causas que la fuerza expansiva del capital. (...) Una ley que, como todas las demás, se ve modificada en su aplicación por una serie de circunstancias que no interesa analizar aquí". (Marx, 1946, p. 546).

Y como lo intuyó Marx, ese fenómeno ocurre sin importar si la remuneración (precio del trabajo humano) es alta o baja. Un par de párrafos más adelante dice: "De donde se sigue que, a medida que se acumula el capital, tiene necesariamente que empeorar la situación del obrero, cualquiera que sea su retribución, ya sea ésta alta o baja. [...] Por eso, lo que en un polo es acumulación de riqueza es, en el polo opuesto, es decir, en la clase que crea su propio producto como capital, acumulación de miseria, de tormentos de trabajo, de esclavitud, de despotismo y de ignorancia y degradación moral”14 (Marx, 1946, p.547). Si bien la lucha organizada de los trabajadores durante el siglo 20 impidió que se llegase a este "dantesco" resultado -que puede coincidir con lo que Piketty (2014, p. 23) llama las predicciones apocalípticas de Marx, idea que nunca estuvo en la mente del Prometeo de Tréveris ${ }^{15}$-, la lógica del desarrollo capitalista se mantiene, por cauces menos violentos.

El gran mérito de Marx es haber señalado que la acumulación no solo produce un acrecentamiento cuantitativo del capital, sino también su cambio cualitativo, lo que nos permite entender, en el transcurso histórico, el paso hacia unidades productivas más complejas y métodos técnicos más perfeccionados, por la introducción de la ciencia al proceso de trabajo. En este movimiento dialéctico ya no solo crece la contradicción antagónica entre los trabajadores y los propietarios de los medios de producción, sino también entre los propios capitalistas. Como escribe Marx (1946, pp. 529-531):

No se trata ya de una simple concentración, idéntica a la acumulación, de los medios de

14 Lo que está en letra cursiva figura así en el original.

15 Título de una biografía de Marx, escrita por Gunter Radczun, y publicada por la Editorial de Ciencias Sociales, de La Habana, 1974, 260 p. 
producción y del poder de mando sobre el trabajo. Se trata de la concentración de los capitales ya existentes, de la acumulación de su autonomía individual, de la expropiación de unos capitalistas por otros, de la aglutinación de muchos capitales pequeños para formar unos cuantos capitales grandes. (...) Se trata de una verdadera centralización, que no debe confundirse con la acumulación y la concentración.

De acuerdo con la percepción de Marx en su momento, "la concurrencia actúa vertiginosamente -dice-, en razón directa al número y en razón inversa al volumen de los capitales que rivalizan entre sí. Y termina siempre con la derrota de los muchos capitalistas pequeños, cuyos capitales son engullidos por el vencedor, o desaparecen". Y más adelante enfatiza: "[...] Dentro de una determinada rama industrial, la centralización alcanzaría su límite máximo cuando todos los capitales invertidos en ella se aglutinasen en manos de un solo capitalista”. A lo que Engels añadió la siguiente nota de pie de página en la cuarta edición de $E l$ Capital: "Los novísimos trusts ingleses y norteamericanos aspiran ya a esto, puesto que tienden a unificar, por lo menos, todas las grandes empresas de una rama industrial, en una gran sociedad anónima con monopolio efectivo" (Marx, 1946, pp. 529-531).
Ya en el desarrollo concreto del capitalismo, el fenómeno de la ascendente centralización que llevase a una o muy pocas empresas que sea fácil identificar como controlantes de una actividad, no ha funcionado como en la previsión de Marx y Engels, pues es contrarrestado desde el punto de vista económico por el fraccionamiento artificial de las empresas según conveniencia de los capitalistas. Hoy en día es frecuente ver que se controla toda una rama o un renglón, esto es, de hecho se tiene un monopolio, pero manteniendo la independencia jurídica y administrativa de las empresas. Desde hace más de un siglo el capitalismo ha encontrado diversos métodos para simular $^{16}$ la competencia. Para el caso de Colombia pueden mencionarse varios ejemplos, pero dos bastan por ahora: la producción y distribución de cervezas y bebidas gaseosas (Silva-Colmenares, 1977, pp. 46-57; Silva-Colmenares, 2004, pp. 55-65 y 195-206).

Para sintetizar, podría decirse que la concentración de la producción expresa la reproducción ampliada, es decir, supone el crecimiento económico, el acrecentamiento de la riqueza para convertir una parte de ella en nuevo capital; expresa las relaciones de producción entre los trabajadores y los capitalistas. En cambio, la centralización del capital no depende tanto de la acumulación, ya que el expresar la diferenciación de los capitalistas es un

$\overline{16}$ El Diccionario de las Academias de la Lengua Española define el verbo simular como "Representar algo, fingiendo o imitando lo que no es". 
mecanismo de redistribución del capital en funcionamiento. Lo anterior nos permite entender que a medida que haya mayor centralización del capital, por fusiones o adquisiciones de empresas, en una rama industrial, y que mayor sea su participación en el mercado, por la concentración de la producción, habrá mayor posibilidad de acuerdos sobre precios y reparto del mercado, como lo comprueban los casos de la producción de azúcar, cemento, derivados del papel, cerveza, bebidas gaseosas y otros renglones en la economía colombiana. Algunos de estos casos están bajo investigación de la Superintendencia de industria y Comercio -SIC-, la autoridad gubernamental colombiana encargada de vigilar que no haya monopolios o empresas con posición dominante en mercados específicos, que les permita estas “ventajas competitivas” que afectan los intereses de los consumidores.

La concentración de la producción ha sido un proceso bien diferenciado en Colombia desde mediados del siglo pasado, pues para la administración de Alberto Lleras (1959-1962) la encuesta manufacturera del DANE arrojó, según la metodología de esta investigación, un promedio para el cuatrienio de más de 10.600 establecimientos con 261.000 trabajadores en total, con un promedio de 24 trabajadores por establecimiento (Centro de Investigación para el Desarrollo-CID-, 1968, pp. 58-67).

Tres gobiernos después (cuatrienio 1975 1978, administración López Michelsen), la situación había cambiado de manera notable: según el mismo método de encuesta manufacturera, el número de establecimientos ${ }^{17}$ había disminuido en $39 \%$, la población ocupada ${ }^{18}$ había aumentado en 83 \% y el número de trabajadores por establecimiento había aumentado en 204 \%. Puede ser que el cambio obedezca a modificaciones en los registros estadísticos utilizados por el DANE o en la versión de la clasificación CIIU utilizada -lo que habría que investigar-, pero esas son las cifras que se encuentran, si se comparan las cifras de la primera línea de la Tabla 5 con el promedio de la administración Lleras Camargo, citadas más arriba.

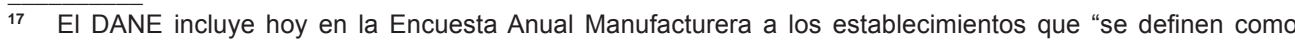
industriales según la clasificación CIIU Re. 3 DANE y que tengan diez o más personas ocupadas”; además, cada año se fija un límite mínimo en el valor de la producción, para tal inclusión; para el año 2013 fue de 137,2 millones de pesos corrientes.

18 Para el DANE, "hace referencia al total de personas ocupadas por los establecimientos industriales, permanentes y temporales contratadas directamente por el establecimiento o a través de agencias. Se incluyen los propietarios, los socios y familiares no remunerados, que desarrollen una labor en el establecimiento y, en aquellas unidades auxiliares que dependen administrativamente de él y que están ubicados en el mismo lugar físico". 
La industria colombiana 1975-2014: inequidad entre trabajo y capital Julio Silva-Colmenares - Carolina Padilla Pardo

Tabla 5. Industria 1975-2014: variables seleccionadas

(Billones de pesos de 2005)

\begin{tabular}{|l|r|r|r|r|l|}
\hline \multicolumn{1}{|c|}{ GOBIERNOS } & PB & \multicolumn{1}{c|}{$\begin{array}{c}\text { No. de } \\
\text { Est. }\end{array}$} & $\begin{array}{c}\text { Total } \\
\text { PO }\end{array}$ & PO/Est. & \multicolumn{1}{c|}{$\begin{array}{c}\text { PB/ } \\
\text { Est. }\end{array}$} \\
\hline Alfonso López Michelsen (1975-1978) & 252,0 & 6,522 & 478,618 & 73 & 38,645 \\
\hline Julio César Turbay Ayala (1979-1982) & 286,9 & 6,868 & 505,752 & 74 & 41,772 \\
\hline Belisario Betancur C. (1983-1986) & 300,4 & 6,399 & 460,117 & 72 & 46,946 \\
\hline Virgilio Barco Vargas (1987-1990) & 376,9 & 7,334 & 487,249 & 66 & 51,399 \\
\hline César Gaviria Trujillo (1991-1994) & 384,0 & 7,603 & 610,251 & 80 & 50,508 \\
\hline Ernesto Samper Pisano (1995-1998) & 374,3 & 8,067 & 625,427 & 78 & 46,406 \\
\hline Andrés Pastrana Arango (1999-2002) & 355,8 & 7,133 & 531,806 & 75 & 49,879 \\
\hline Álvaro Uribe Vélez (2003-2006) & 436,8 & 7,343 & 579,116 & 79 & 59,480 \\
\hline Álvaro Uribe Vélez (2007-2010) & 489,4 & 8,569 & 649,369 & 76 & 57,118 \\
\hline Juan Manuel Santos (2011-2014) & 569,5 & 9,362 & 679,022 & 73 & 60,830 \\
\hline \% de variación 2011-14/1975-78 & $125,9 \%$ & $43,5 \%$ & $41,9 \%$ & $-1,2 \%$ & $57,4 \%$ \\
\hline TAG Periodo 1976-2014 (39 años) & $2,3 \%$ & $0,9 \%$ & $1,0 \%$ & & \\
\hline
\end{tabular}

Fuente: DANE - Encuestas Anuales Manufactureras - Cálculos de los autores.

$\mathrm{PB}=$ Pruducción Bruta - Corresponde al acumulado en cada cuatrienio

Est. = Establecimientos - Corresponde al promedio anual de establecimientos en cada cuatrienio

$\mathrm{PO}=$ Población ocupada - Corresponde al promedio anual de personas ocupadas en cada cuatrienio

En el lapso que se utiliza para este artículo la situación es más estable, aunque es evidente la concentración de la producción. Mientras el número de establecimientos y la población ocupada, que incluye a los trabajadores temporales directos e indirectos, aumentaron en más del 40 \% durante los diez gobiernos, según las encuestas anuales manufactureras del DANE, manteniéndose casi inalterable el promedio de trabajadores por establecimiento (un poco más de 70 en los cuatrienios inicial y final), la producción media por establecimiento, medida en pesos de 2005, aumentó en un $57 \%$, pasando de 38.645 millones en el cuatrienio 1975-1978 a 60.830 millones en 2011-2014, como puede verse en la Tabla 5.
Pero la concentración de la producción no es un fenómeno reciente en Colombia. Como se lee en los párrafos iniciales sobre la industria manufacturera en SilvaColmenares (1977, p. 20)

cada día las fábricas son más grandes, en promedio, cuanto por el número de trabajadores como por la producción realizada. Así, si en 1957 el promedio de trabajadores por establecimiento era de 50,2, ya para 1972 había subido a 77,7, lo cual implica un aumento de más de la mitad (54,8\%). Si comparamos la producción de 1957 con la de 1972, en pesos constantes de 1957, el promedio es de $\$ 1,8$ millones para 1957 y \$3,7 millones para 
1972, o sea un aumento del 105,6\% en el período. Esto significa que el crecimiento real de la producción por empresa es más del doble que el del empleo, lo cual obedece, entre otras causas, a mayor tecnificación (industrias de más alta intensidad o composición orgánica del capital) y mayor explotación de los trabajadores". En resumen, se dice a continuación: "el número de empresas aumentó en los 15 años en un $25 \%$, el empleo lo hizo en un 93,5\% y la producción, en valores constantes, en un $157,8 \%$. [...].

Por consiguiente, desde mediados del siglo pasado era evidente la concentración de la producción y la elevación de la productividad laboral, lo que hace más lenta la creación de empleo y facilita, en condiciones de un mercado monopólico, que la reducción de costos que permite una mayor productividad se traslade a las ganancias empresariales, con poca o ninguna participación de los trabajadores.

Otros trabajos ya habían detectado un nivel alto de concentración monopólica. Misas (1968), citado por (Silva-Colmenares, 1977, p. 23-24) encontró en su momento que en 16 renglones industriales que representaban el 24,8 \% de la producción total el grado de concentración era A (del $75 \%$ al $100 \%$ fue producido por tres firmas, como máximo); al adicionar los 26 renglones con el grado de concentración B (del $50 \%$ al $75 \%$ fue producido por las cuatro firmas mayores) la participación en la producción subía al 42,6 \% y en el valor agregado al 53,2 \%, lo que significaba que alrededor de la mitad de la producción industrial correspondía a un manejo monopolístico de alta y mediana concentración.

Años después, Misas (1993, p. 13-14) dice que: "en el lapso transcurrido entre 1968 y 1984 el grado de concentración en la industria colombiana se incrementó en forma significativa. El $60 \%$ de la producción se efectúa en industrias mediana y altamente concentradas", teniendo en cuenta la producción de las cuatro mayores firmas en cada renglón industrial. Al examinar el grado de concentración según categoría de los bienes producidos, propone las "siguientes conclusiones, que resultan de especial importancia: i) en la producción de bienes intermedios hay un predominio absoluto de las formas oligopólicas; ii) en la producción de bienes de consumo se aprecia un incremento apreciable de los oligopolios, en especial de los altamente concentrados; y iii) la producción de bienes de capital se desarrolla bajo condiciones oligopólicas con un grado medio de concentración”.

Y más adelante plantea:

durante la década de los setenta, simultáneamente con la consolidación de la estructura oligopólica, en la economía se fue generando un conjunto de fenómenos que debilitaron las iniciativas tendientes a expandir la demanda de bienes manufacturados, especialmente 
de bienes de consumo durables. Las medidas que hacían compatible la expansión oligopólica y sus procesos de diferenciación e introducción de nuevos productos al mercado con una muy desigual distribución del ingreso, pusieron en evidencia fricciones y contradicciones, que luego se tradujeron en menores ritmos de crecimiento del consumo de bienes manufacturados, lo que vino a agravar la enfermedad crónica de la economía colombiana: la insuficiente demanda efectiva. (Misas, 1993, pp. 18-19).

En la primera década del siglo 21 se mantiene esta situación. Un estudio sobre medición de la concentración en la industria manufacturera encontró que "el promedio de concentración para el total de la industria en 2001 ascendió a 0,41, en tanto que para 2010 éste fue de 0,39”, utilizando el índice Herfindahl-Hirschman en 60 actividades industriales; si bien el grado de concentración disminuyó un poco durante este lapso, recuérdese que para esta aplicación un índice superior a 0,25 se considera una concentración alta. Como se lee en este documento: "Las actividades agrupadas en la categoría de concentración alta representan 73\% del total de la industria [...] Este grupo captura el $44 \%$ de los establecimientos, $59 \%$ del empleo y $80,3 \%$ del valor agregado". Según este estudio:

actividades como la producción de aparatos de uso doméstico (CIIU 293), construcción y reparación de buques (CIIU 351), productos de la refinación de petróleo (CIIU 232), ingenios, refinerías de azúcar, y trapiches (CIIU 157), vehículos automotores (CIIU 341), hilos y cables aislados (CIIU 313), aeronaves y naves espaciales (CIIU 353), tabaco (CIIU 160), receptores (CIIU 323) y transmisores (CIIU 322) de radio y televisión, arrojaron índices de concentración que oscilan entre 0,7 y 1 ". Actividades como "fabricación de productos minerales no metálicos (CIIU 269), servicios relacionados con la impresión (CIIU 223), caucho (CIIU 251), fabricación de sustancias químicas básicas (CIIU 241), textiles no producidos en la misma unidad (CIIU 173), partes y piezas de carpintería (CIIU 203) y fabricación de vidrio (CIIU 261), muestran un nivel de concentración entre 0,25 y 0,30. (Sáenz, 2014, p. 17)

El estudio plantea en las conclusiones:

Estos resultados concuerdan con lo encontrado por Misas G. (1975 y 1988) y Garay Luis J. (2004). En los estudios de Misas se encuentra un incremento de la concentración industrial entre 1968 y 1984, mientras que los hallazgos de Garay señalan que la industria manufacturera colombiana se caracterizó por tener un alto nivel de concentración. Según Garay, en 1991 el 70\% de la producción manufacturera fue generada por 
sólo 500 establecimientos. De acuerdo con los resultados obtenidos del grado de concentración en la industria manufacturera según el número de establecimientos, y el nivel generado de empleo y valor agregado aportado por cada uno de ellos, la industria manufacturera en Colombia tiende a presentar estructuras de mercado de tipo oligopólico. El caso extremo se observa en algunos sectores como: refinación de petróleo, elaboración de bebidas y otros productos químicos, que muestran una elevada participación en el valor agregado y un bajo porcentaje en la generación de empleo y en el número de establecimientos, lo que permite deducir la presencia de estructuras de mercado monopólicas en este tipo de actividades industriales. (Sáenz, 2014, p. 27).

Los beneficiarios de esta situación pueden identificarse, pues cada vez son menos y más poderosos, gracias al proceso de centralización del capital. Como se dijo en la Introducción a Los verdaderos dueños del país:

En nuestra indagación sobre el poder de los monopolios y la oligarquía descendemos al mundo de la economía práctica, y en lugar de enfrascarnos en divagaciones teóricas, paseamos por cada sector de la actividad productiva, escogemos las principales industrias o subsectores, buceamos en los renglones, productos o servicios básicos y allí nos detenemos a buscar las empresas que los controlan y a identificar sus propietarios. [...] Ante el gran perjuicio que causan al país los monopolios nacionales y extranjeros, no faltan voces -a veces desde los mismos altos cargos gubernamentales-- que se levantan para condenarlos, pero todas se quedan en el monopolista abstracto, sin nombre ni empresas. Como consideramos que este inicuo juego no puede continuar, aquí presentamos nombres y apellidos, razones sociales y aún damos un paso más: buscamos la forma cómo se entrelazan, cómo se respaldan mutuamente, hasta que dejan de ser monopolistas aislados para fundirse en la fuerza multiplicada del grupo financiero. [...]. (Silva-Colmenares, 1977, p. 9).

Como comprobación resumida de la centralización del capital desde hace varias décadas, puede recordarse que para 1974 los diez grupos financieros más grandes presentes en Colombia poseían activos bajo su control directo cercanos a 160.000 millones de pesos colombianos corrientes, lo que equivalía a una cifra cercana al $50 \%$ del PIB, que para ese año sumó, en términos redondos, 325.000 millones de pesos corrientes (Silva-Colmenares, 1977, p. 310).

Como se muestra en el libro El gran capital en Colombia, (Silva-Colmenares, 2004, pp. 23-24), para principios del siglo 
21 también los diez principales grupos financieros (como es comprensible, no los mismos de 1974) habían multiplicado los activos bajo su control en más de 600 veces y sumaban un poco más de 97 billones de pesos corrientes, magnitud cercana al $50 \%$ del PIB, lo que muestra que en los 25 años habían mantenido un férreo control sobre la economía colombiana. El principal grupo en ese momento correspondía al que desde los años setenta fue "bautizado" como grupo Suramericana, y que algunos llaman el Sindicato Antioqueño y otros el Grupo Empresarial Antioqueño, con unos activos equivalentes al 15,7 \% del PIB, unos 11.500 millones de dólares estadounidenses, cuando en los años setenta ocupaba el cuarto puesto, con activos equivalentes al 7,3 \% del PIB; es decir, más que duplicó su peso relativo. Le seguía el grupo Santodomingo con activos equivalentes al 10,9 \% del PIB, unos 8.000 millones de dólares, cuando en los años setenta tenía el 4,6\%; o sea que también más que duplicó su peso relativo. En tercer lugar estaba el grupo Sarmiento Ángulo con activos equivalentes al 10,5 \% del PIB, unos 7.700 millones de dólares, cuando en los años setenta, cuando se le identificó como grupo Bogotá, tenía el $9 \%$.

Más adelante se afirma:

algunos de los grupos que figuraban en los años setenta del siglo pasado desaparecieron como tal, aunque la mayoría de las empresas que eran insignia en su momento sólo han cambiado de «dueño». Que es la característica principal en el fenómeno de la centralización del capital en Colombia: cambia la forma, la apariencia, pero se consolida y fortalece el contenido, la esencia. Hoy, como ayer, la altísima centralización del capital no sólo nos confirma que el país sigue teniendo unos pocos pero verdaderos dueños, con la consiguiente concentración del ingreso, mientras en el otro lado de la moneda la mitad de la población padece la «enfermedad social» de la pobreza y su síndrome más grave, la miseria. Colombia fue durante el siglo 20 un «modelo» de sociedad excluyente y atrasada, con una economía cerrada y monopolizada. (Silva-Colmenares, 2004, pp. 2627).

\section{CONCLUSIONES}

En los párrafos anteriores se describieron varios fenómenos del capitalismo que se han intensificado en las últimas décadas. Así pues, los cambios en los modos de producción de bienes y servicios, el surgimiento de nuevas formas de trabajo humano y la consolidación de cadenas globales de valor conformadas por grandes empresas o por conglomerados empresariales exigen un debate político sobre la desigualdad y la forma en que estos cambios pueden exacerbarla. Gran parte de los trabajos académicos sobre el tema utilizan como referente las medidas de dispersión o de concentración del ingreso que perciben las personas o las 
familias pero dejan de lado la manera cómo se distribuye la riqueza creada entre los “agentes económicos". Por consiguiente, al analizar la distribución funcional del ingreso en la industria, se evidencia que a pesar de que el trabajo humano se ha "enriquecido", al aumentar su conocimiento acumulado, años de escolaridad y expectativa de vida, por tanto, ha aumentado de "valor"; los trabajadores, como clase social, reciben cada vez una menor parte de la riqueza creada, por lo que como clase social se empobrecen.

Ahora bien, esta inequitativa distribución de la riqueza creada se da en el marco de una alta concentración de la producción industrial junto con la elevación de la productividad laboral. Esta concentración ha hecho más lenta la creación de empleo y ha facilitado, en condiciones de un mercado monopólico, la reducción de costos que eleva la competitividad y aumenta las ganancias empresariales, con poca o ninguna participación de los trabajadores.

Por último, la evolución del empleo en la industria colombiana evidencia una precarización de las condiciones de empleo que se refleja en el aumento de los trabajadores informales. Esto es preocupante, pues a pesar de las mejores condiciones de la fuerza laboral y la elevación de su productividad, los salarios y las condiciones de contratación son cada día más inestables, por lo menos para los trabajadores menos calificados. Cabe resaltar que los hallazgos de este trabajo señalan la necesidad de estudiar con más detalle fenómenos propios de “deformación” en la estructura industrial en capitalismos "tardíos" y de “monopolización precoz”, como es el caso colombiano.

\section{REFERENCIAS}

Centro de Investigación para el Desarrollo -CID-. (1968). Industria manufacturera fabril. Monografía estadística 1958 - 1967, cuadros: 1, 2, 3, 5, 7, 12, 14, 16 y 22. Bogotá: Universidad Nacional de Colombia.

Departamento Administrativo Nacional de Estadística -Dane- . (2008, 3 de julio). Boletín de Prensa Encuesta Anual Manufacturera-EAM-2006. Recuperado de http://www.dane.gov.c o/files/investigaciones/boletines/eam/bolet_eam_2006. pdf

Departamento Administrativo Nacional de Estadística -Dane-. (2015, 8 de mayo). Boletín Técnico Encuesta Anual Manufacturera -EAM-, correspondiente al año 2013, p. 35. Recuperado de http://www.dane.gov.co/files/investigaciones/ boletines/eam/Anex_2013pr.pdf 
Economía y Negocios (2016, 26 de abril). Los sectores con más y con menos empleo formal. El Tiempo, 1.

Grupo de Estudios del Crecimiento Económico Colombiano -Greco- (2002). El crecimiento económico colombiano en el siglo XX. Bogotá: Fondo de Cultura Económica.

Gutiérrez, N. G. (2016, 15 de abril). Se busca robot con experiencia: empleos humanos y robots en la globalización. Recuperado de http://globalización.org

Marx, C. (1946). EI Capital. Crítica de la economía política. Tomo I. México: Fondo de Cultura Económica.

Méndez, S. J. \& Hernández, E. H. (2014, julio-diciembre). Relación de largo plazo y análisis de causalidad y sensibilidad entre los salarios reales y la productividad laboral en el sector manufacturero a partir de cifras de los departamentos en Colombia. Revista Finanzas y Política Económica, Universidad Católica de Colombia, 6(2), 341-366.

Misas, G. (1968 ). Contribución al estudio del grado de concentración en la industria colombiana. Bogotá: Departamento Administrativo Nacional de Estadística -Dane-.

Misas, G. (1993). El papel de las empresas transnacionales en la reestructuración industrial de Colombia: una síntesis. Santiago de Chile: Estudios e Informes de la Cepal.

Organización Internacional del Trabajo -OIT-(2012). Del trabajo precario al trabajo decente: documento final del simposio de los trabajadores sobre políticas y reglamentación para luchar contra el empleo precario. Ginebra, Suiza: OIT.

Piketty, T. (2014). El capital en el siglo XXI. Bogotá: Fondo de Cultura Económica.

Programa de las Naciones Unidas para el Desarrollo -PNUD-. (2016). Informe sobre Desarrollo Humano 2015. Nueva York: ONU.

Restrepo, N. (2011). Empresariado antioqueño y sociedad 1940-2004. Transformación e influencia de las élites patronales de Antioquia en las políticas socioeconómicas colombianas a partir de 1940. Medellín: Universidad de Antioquia.

Revista Dinero. (2016, 19 de feb.). La clave para entender el surgimiento de la cuarta revolución industrial. Revista Dinero, (487), 18. 
Sáenz, J. E. (2014). Medición de la concentración de la industria manufacturera colombiana: una aproximación a partir del índice de Herfindahl-Hirschman para 2001 y 2010. Documento de Investigación, Corporación Universitaria de Ciencia y Tecnología-Uniciencia, 29.

Samper, C. A. (2016). Relación entre salarios reales y productividad real en la industria manufacturera colombiana: análisis de datos panel 1970-1989 y 1990 2012. Trabajo para optener el título en la Maestría en Ciencias Económicas, Universidad Santo Tomás, Bogotá, Colombia.

Schwab, K. (2016, 5 de junio). Las dos caras de la moneda. El Tiempo.

Silva-Colmenares, J. (1977). Los verdaderos dueños del país. Oligarquía y monopolios en Colombia. Bogotá: Suramérica.

Silva-Colmenares, J. (2004). El gran capital en Colombia. Proyección al siglo XXI. Bogotá: Planeta.

Silva-Colmenares, J. (2013). Colombia: crecimiento económico y desarrollo humano. Algunas características en el lapso 1959-2010. En varios autores, Globalización, crecimiento y desarrollo (pp. 87-166). Bogotá: Academia Colombiana de Ciencias Económicas.

Silva-Colmenares, J. (2014, primer semestre). En torno a la discusión sobre «desindustrialización». Un sucinto análisis respecto a la producción bruta y el producto interno bruto. Tendencias (Universidad de Nariño), 15(1), 109-130.

Silva-Colmenares, J. (2015). Divergencia entre valor y precio del trabajo. Un complemento a la obra El capital en el siglo XXI de Piketty. En varios autores, Piketty y los economistas colombianos. Debate sobre el capital en el siglo XXI (p. 379 ). Bogotá: Aurora.

Silva-Colmenares, J. \& Padilla-Pardo, C. (2015). Transnacionalización de empresas colombianas. Conglomerados que cruzan fronteras. Bogotá: Universidad Autónoma de Colombia.

Smith, A. (1994). La riqueza de las naciones. Madrid: Alianza.

Tinoco, C. \& Soler, S. (2011, enero-junio). Aspectos generales del concepto de "capital humano”. Criterio Libre, 9(14), 203-226. 